\title{
Subtotal laparoscopic splenectomy in rats with preservation of the inferior pole ${ }^{1}$
}

\author{
Esplenectomia subtotal laparoscópica com preservação do polo inferior em ratos
}

\author{
José Jorge da Silva', Alcino Lázaro da Silva"I, Danilo Nagib Salomão Paulo ${ }^{I I I}$ \\ ${ }^{1}$ Research performed at the Laboratory of the Division of Surgical Principles, Department of Surgery, School of Science, Santa Casa de Misericórdia, \\ EMESCAM, Vitoria-ES, Brazil. \\ ${ }^{I}$ Fellow Master degree, Postgraduate Program in General Surgery, Minas Gerais Federal University (UFMG), Brazil. Main author. Involved with \\ technical procedures and manuscript writing. \\ ${ }^{\text {II }}$ Professor Emeritus of Surgery, School of Medicine, UFMG, Minas Gerais, Brazil. Critical revision.

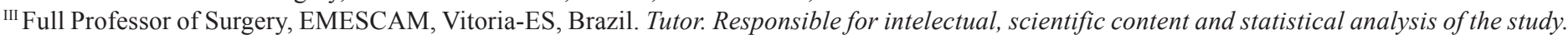

\begin{abstract}
Purpose: To evaluate the feasibility and safety of subtotal splenectomy by laparoscopy with inferior pole preservation and to determine the viability of the splenic remnant. Methods: Twenty male Wistar rats weighing between $365 \mathrm{~g}$ and $474 \mathrm{~g}$ (mean 417.92 $\pm 36.15 \mathrm{~g} \mathrm{SD}$ ) were operated and randomly assigned to two groups : Group 1 rats were killed on postoperative day 10 ( $\mathrm{n}=10)$, and Group 2 on the postoperative day $80(\mathrm{n}=10)$. Both the inferior splenic pole and the superior part of the spleen, which was used as a control to measure inferior pole viability, were weighed and morphologically examined. Results: The technique was feasible in all cases. There were two postoperative deaths on immediate postoperative and one not well defined. The average weight percentage of the inferior pole, measured indirectly on the 10 th day, was $53.67 \% \pm 11.59 \%$ and on the 80 th day was $62.69 \% \pm 6.89 \%$. The inferior pole was necrotic, with abscess formation in one case (5.9\%) and appeared normal in all other cases. Microscopy showed features that were compatible with normality. Conclusions: Subtotal splenectomy with preservation of the inferior pole by laparoscopy was feasible and safety. The lower splenic pole was viable in $94.1 \%$ of animals.
\end{abstract}

Key words: Spleen. Splenectomy. Laparoscopy. Rats.

\section{RESUMO}

Objetivo: Avaliar a exequibilidade e a segurança da esplenectomia subtotal com preservação do polo inferior do baço por videolaparoscopia, e a viabilidade do referido polo. Métodos: 20 ratos Wistar, machos, pesando entre 365g e 474g (MA 417,92 $\pm 36,15 \mathrm{~g}$ ) foram operados e distribuídos em dois grupos de acordo com a época da retirada do polo inferior para estudo: grupo 1 do $10^{\circ}$ dia, $(n=10)$, grupo 2 , do $80^{\circ}$ dia $(n=10)$. A porção superior do baço que serviu de controle da viabilidade do pólo inferior e esse remanescente, retirados no término do experimento, foram medidos, pesados e enviados para exame morfológico. Resultados: A técnica foi exeqüível em todos os casos. O peso médio percentual do polo inferior avaliado de forma indireta no $10^{\circ}$ dia foi $53,67 \% \pm 11,59 \%$, e no $80^{\circ}$ dia $62,69 \% \pm 6,89 \%$. Houve dois óbitos após a cirurgia, provavelmente por mal condução da anestesia e/ou do pneumoperitônio, e um tardiamente por causa desconhecida. O exame macro e microscópico do polo inferior nos 17 animais sobreviventes e no que faleceu tardiamente mostrou necrose em um caso (5,9\%). Conclusões: A esplenectomia subtotal com preservação do pólo inferior por videolaparoscopia em ratos foi exequível e segura. O polo inferior do baço mostrou-se viável em $94,1 \%$ dos animais.

Descritores: Baço. Esplenectomia. Laparoscopia. Ratos.

\section{Introduction}

Total splenectomy may cause complications ${ }^{1}$, the most feared of which are infections ${ }^{2}$, as observed in experimental animals $^{3}$. Changes in lipid metabolism have also been described in humans ${ }^{4}$ and in experimental animals ${ }^{5}$, where these can lead to atherosclerosis ${ }^{6}$. Thus, non-operative treatment of splenic trauma, as well as operations for total or partial splenic preservation, is increasingly valued. The advent of laparoscopic surgery with
Mühe ${ }^{7}$ in 1985 in Germany and laparoscopy from Mouret ${ }^{8}$ in 1987 in France motivated surgeons to develop minimally invasive technical modalities to diagnose and treat acute and chronic diseases of the abdominal cavity. The spleen is an abdominal organ that is easily accessible by laparoscopy. Surgery on this organ is facilitated by the great magnification of the objective lens of the laparoscope (up to 20-fold). One can identify the splenic 
pedicle and its segmental branches and perform a splenectomy. Laparoscopic spleen surgery began in the 1990s. Initially, total and partial splenectomies ${ }^{9}$ were performed on humans ${ }^{10}$ and experimental animals ${ }^{11,12}$. Partial splenectomy that preserved the inferior pole, a more recent alternative for spleen-conserving surgery, was described in experimental animals via laparotomy. The technique was feasible, and the inferior pole was viable in $86.6 \%$ of the cases ${ }^{13}$. Until recently, partial splenectomy by laparoscopic access and viability of the remaining inferior pole have not been described.

The objective of this study was to evaluate the feasibility and safety of partial splenectomy by laparoscopy that preserves the inferior pole and to study, after two distinct time intervals, the viability of the remainder of the spleen after the operation.

\section{Methods}

This work was performed at the Fundamentals of Surgery Laboratory, College of Science of Santa Casa de Misericordia de Vitoria-Emescam, following approval from the Ethics Committee of the Minas Gerais Federal University.

The animals were placed in collective cages, each with a capacity of five animals, and were fed with commercial pellets for laboratory animals (Mill Primor MP-77, Sao Paulo). The bottom of each cage was lined with shavings, and the ceiling was covered with a metal grille. The rats underwent clinical examinations to rule out underlying conditions, and were subsequently returned to their cages for an adaptation period of 15 days.

Twenty Wistar rats were used in this experiment, each weighing between $365 \mathrm{~g}$ and $474 \mathrm{~g}$ (mean $417.92 \pm 36.15$ ) and approximately 12 weeks old. The rats were obtained from the vivarium of the School of Sciences of Santa Casa de Misericordia de Vitoria-ES (Emescam).

The rats were distributed into two groups with the aid of a random numbers table prepared by a statistician, according to the period during which the inferior pole (IP) was removed for the study: in Group $1(\mathrm{n}=10)$, the IP was taken out on the 10th day after surgery, whereas in Group $2(\mathrm{n}=10)$, the IP was removed on the 80th day after surgery The rats were fasted for eight hours and then subjected to the subtotal laparoscopic splenectomy ( SSL/IP) following procedures:

- Anesthesia with ketamine hydrochloride at a dose of $50 \mathrm{mg} / \mathrm{kg}$ and xylazine hydrochloride at a dose of $2.5 \mathrm{mg} / \mathrm{kg}$ intraperitoneally, weighing (electronic scale Filizola ${ }^{\circledR}$-sensitivity to $1 \mathrm{~g}$ ) and identification by a mark on the ear (with a linear cut for group 1 and $\mathrm{V}$-cut for group 2);

- Removal of the fur on abdominal wall at the trocar insertion area;

- Placement in the supine position on the operating table (handled by the feet);

- Antisepsis of the abdominal skin with iodinated alcohol and draping of the surgical field;

- Insertion of the primary $10-\mathrm{mm}$ trocar into the lower left quadrant of the abdomen under direct visualization (A);
- Introduction of the 2 nd trocar $(5-\mathrm{mm})$ in the right hypochondrium, guided by laparoscopy, through which the Maryland (B) forceps were introduced;

- Placement of the third 5-mm trocar (C) in the lower right quadrant, also directed by laparoscopy, through which the clipper was introduced (Figure 1).

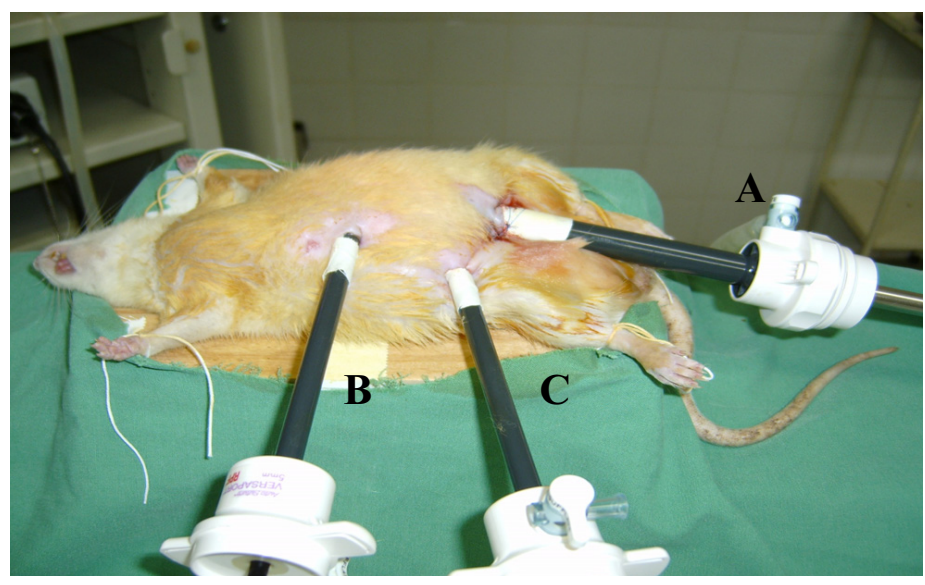

FIGURE 1 - Position of the three trocars on the rat abdominal wall for subtotal laparoscopic splenectomy with preservation of the inferior pole. Abdominal distension by pneumoperitoneum was observed. A. 10-mm trocar introduction under direct vision in the lower left quadrant, B. Trocar (5-mm) through which the Maryland forceps were inserted, right superior quadrant; C. Trocar $(5-\mathrm{mm})$ through which the clipper was introduced, right lower quadrant.

- The locations of the spleen and gastrosplenic ligaments were determined by the surgeon by applying traction with the Maryland forceps to expose the splenic hilum;

- Dissection and clamping of segmental vessels leading from the superior splenic portion to the inferior pole, with preservation of vessels in the gastrosplenic ligament that supplied the inferior pole (Figure 2);

- Use of the L200 Ethicon ${ }^{\circledR}$ staples, Endoview ${ }^{\circledR}$ clipper, and 5-mm trocar;

- Sectioning the spleen and removing the superior portion with preservation of inferior pole vessels supplied by the gastrosplenic ligament (Figure 3);

- Hemostasis at the incision with local compression;

- Preservation of a thin peritoneal fold that connects the greater antral curvature to the anterior part of the inferior pole (Figure 3);

- Deflation of pneumoperitoneum and removal of the trocars;

- Suturing the abdominal skin wound and the underlying muscles with 4-0 mononylon sutures;

- Application of topical povidone iodine on the sutured wound.

The superior portion that was removed was fixed in $10 \%$ formalin for future microscopic study. This fragment served as a control for analysis of the viability of the inferior pole. 


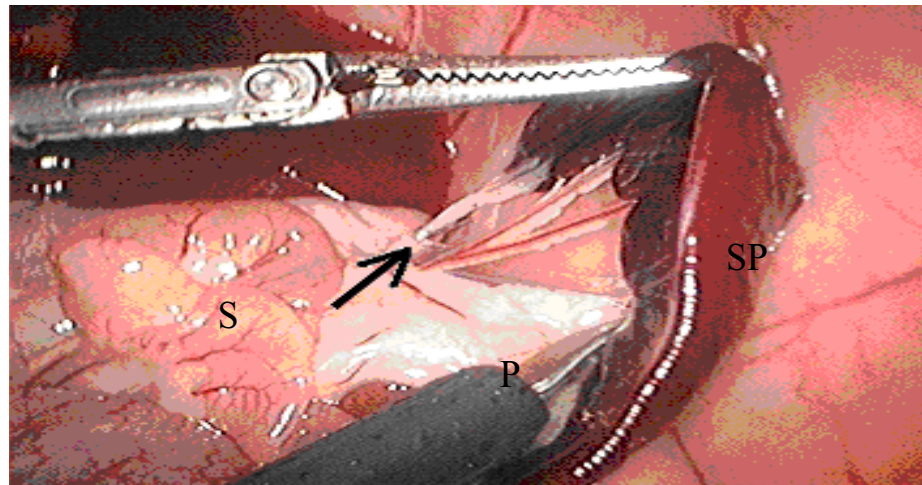

FIGURE 2 - Photograph showing exposure of vessels from the superior spleen in rats that were clipped (arrow) during laparoscopic surgery. S - Stomach. P - Pancreas. SP - Spleen

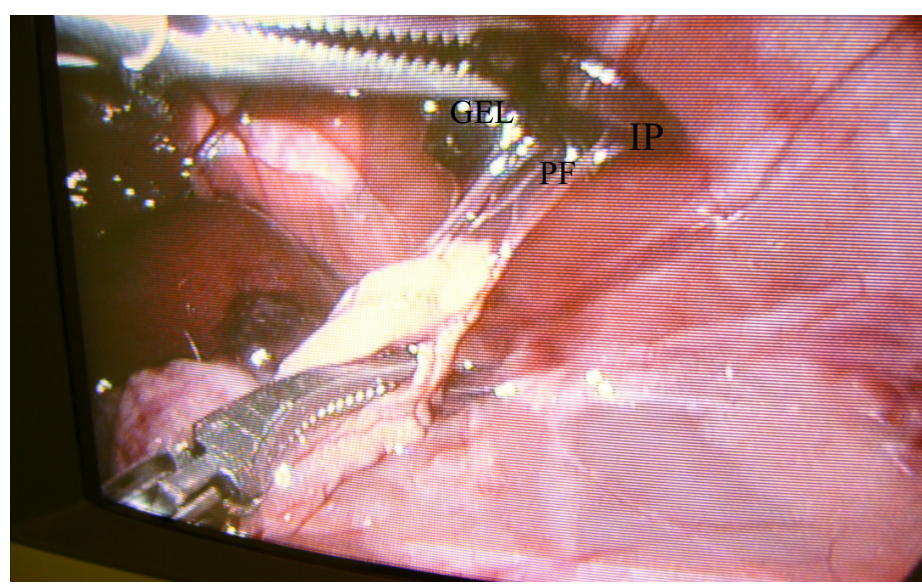

FIGURE 3 - Photograph of the video monitor showing a detail of the inferior pole (IP) of the rat spleen, which is supplied by existing vessels in the gastrosplenic ligament (GEL). A thin peritoneal fold (PF) was observed overlying the vessels that went from the greater antral curvature to the IP.

At the end of surgery, the animals were returned to their cages. In the immediate postoperative period, the rats received paracetamol orally at a dose of $200 \mathrm{mg} / \mathrm{kg}$, dissolved in drinking water, as well as diet and water ad libitum.The animals that died were autopsied, and those that survived were killed on postoperative day 10 (Group 1) or 80 (Group 2) with a lethal intraperitoneal dose of sodium pentobarbital. At the time of sacrifice, the rat was weighed, and an incision was made in the form of an inverted $\mathrm{U}$ on the abdominal wall in order to study the cavity and remove the splenic remnant. After macroscopic analysis, the inferior pole was weighed and sent for histological examination after fixation in $10 \%$ formalin. The superior portion (removed during SSL/IP) and the inferior pole were embedded in paraffin, and sections were stained with hematoxylin-eosin. Analysis of the tissue was performed by a pathologist with a binocular microscope. The sections were analyzed for morphological alterations. The focus of our analysis was splenic viability.

\section{Statistical analysis}

Descriptive statistics were used to calculate the arithmetic mean and standard deviation of the weights of the two rat groups and the weight of the superior and inferior poles of the SSL/IP group.

Linear regression analysis was used to calculate the mass percentage of the remaining inferior pole at the 10th and 80th postoperative days. This was accomplished by dividing the weight of this splenic pole by the ideal weight for each animal in each group. The ideal splenic weight was calculated using the following formula: splenic weight $(=(1.80 \mathrm{x}$ body weight $)+$ 230.49. The average percentage of the remaining splenic mass with its respective standard deviation was then calculated.

Student's t-test was used for related samples to compare the weight of the rats at the beginning of the experiment with weight at the end of the experiment within the same group.

\section{Results}

Performance of SSL/IP was feasible in all cases and was efficacious and safe.

Three rats died postoperatively in the 80-day group. Two deaths occurred soon after surgery, and one death occurred in the late postoperative period. Autopsy of these animals did not identify a specific cause. At the time of autopsy, the inferior pole was macroscopically preserved in the animals that died in the late postoperative period. For the two animals that died during the immediate postoperative period, analysis was inconclusive because it could not predict the likely evolution of the apparently normal remnants. insertion.

No complications were observed at the sites of trocar

The weight of animals subjected to SSL/IP in the 10-day and 80-day groups at the beginning and end of the experiment can be seen in Table 1 .

TABLE 1 - Changes in weights of animals subjected to SSL/IP from the beginning to the end of the experiment.

\begin{tabular}{|c|c|c|c|c|c|}
\hline \multirow[t]{3}{*}{ Groups } & \multicolumn{4}{|c|}{ Weight of the Animals ( $g$ ) } & \multirow{3}{*}{$\mathrm{p}$} \\
\hline & \multicolumn{2}{|c|}{ Beginning of Experiment } & \multicolumn{2}{|c|}{ End of Experiment } & \\
\hline & $\mathrm{AM}$ & $\mathrm{SD}$ & $\mathrm{AM}$ & SD & \\
\hline $1-10 \mathrm{~d}$ PO $\quad(n=10)$ & 402.0 & \pm 45.52 & 433.8 & 20.78 & 0.02 \\
\hline 2- 80 d PO $\quad(n=10)$ & 372.5 & $7 \pm 43.08$ & 433. & \pm 60.93 & 0.007 \\
\hline
\end{tabular}

SSL/IP- Subtotal splenectomy by laparoscopy with preservation of the inferior pole. Student's $t$-test for related samples. $\mathrm{p} \leq 0.05$, significant. AM - Arithmetic mean, SD - Standard deviation. Group 1 - animals killed on the 10th postoperative day. Group 2 - animals killed on the 80th postoperative day. 
The abdominal cavity displayed mild adhesions in both groups (day 10 and day 80). These adhesions were observed between the inferior pole and the stomach and greater omentum.

In our analysis of 17 of the 20 rats operated on, there was only one case of necrosis, with an abscess in the inferior pole $(5.9 \%)$; this occurred in one animal in Group 2. The other poles were grossly normal (94.1\%) (Figure 4).

The average weight percentage of the inferior pole, calculated with the aid of linear regression analysis, was $53.67 \pm$ $11.59 \%$ on the 10 th and $62.69 \pm 6.89 \%$ on the 80 th postoperative day $(\mathrm{p}=0.10)$.

In Group 1 (10 days), the superior and inferior pole exhibited structural preservation. In the white pulp, mild lymphoid hyperplasia was observed. The red pulp displayed sinusoidal dilatation with endothelial hyperplasia and mild to moderate congestion. Macrophages with hemosiderin were also seen (Figure 5). There were no significant differences between the superior and the inferior pole.

In Group 2 (80th day), the white pulp had moderate lymphoid hyperplasia. The red pulp sinusoids appeared to be collapsed, with slight endothelial hyperplasia. A slight increase in the amount of lymphocyte traffic and the presence of macrophages containing hemosiderin were observed. In the samples from inferior poles, there was a greater concentration of macrophages with hemosiderin compared to samples from the superior portion (Figure 6). Sinusoidal dilatation was present in samples from the inferior pole. Stromal sclerosis was also seen in samples from the superior portion but not in samples from the inferior pole.

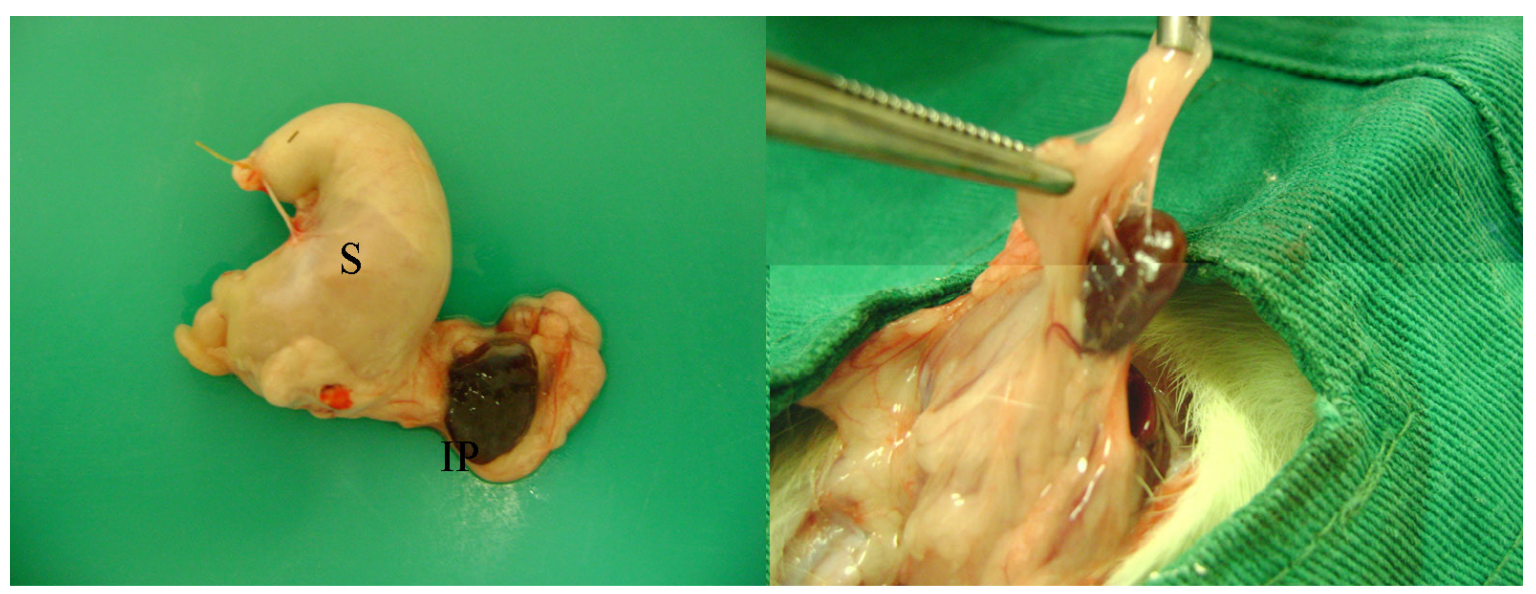

A

B

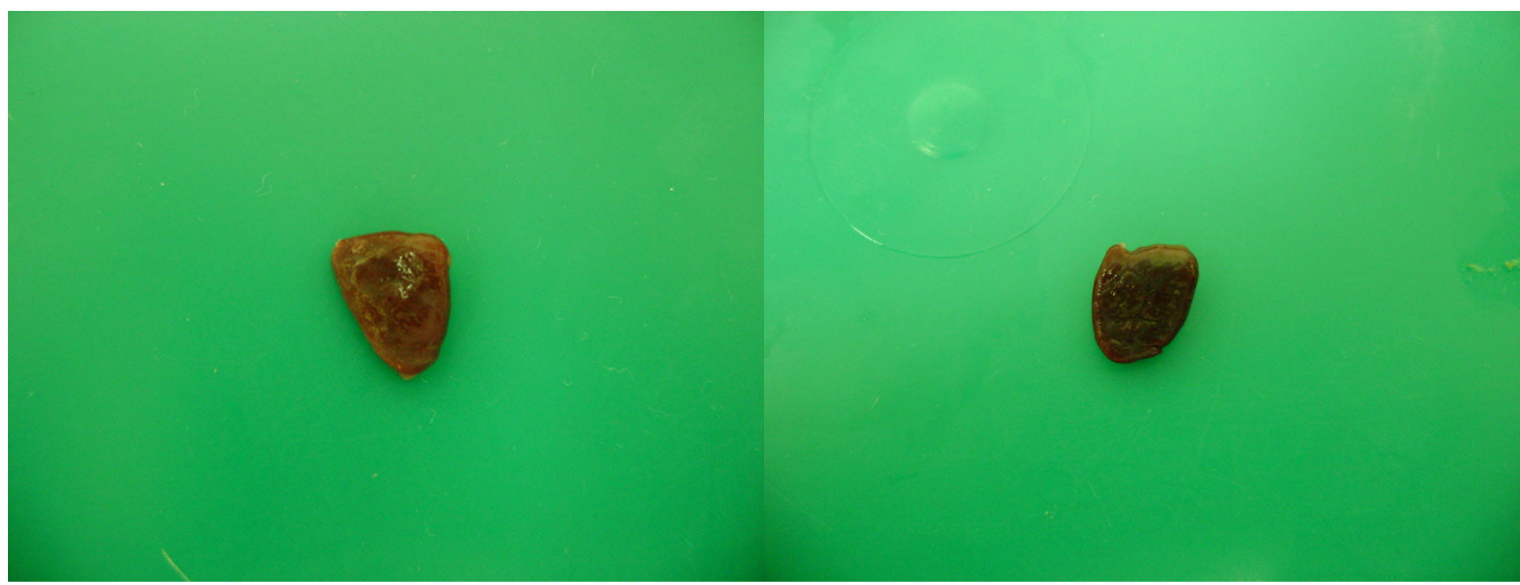

$\mathbf{C}$

D

FIGURE 4 - A. Inferior pole after 10 days. We observed that the macroscopic aspect was normal. The pole below should not be fixed to any abdominal structure, and its cut surface should be facing upwards (cranially); B. Inferior pole on day 80 , adhering to the greater omentum; the vessels were observed to run between the omentum and pole; $\mathbf{C}$ and $\mathbf{D}$. Aspects of the inferior pole isolated on day $80 . \mathbf{S}$ - stomach. IP - inferior pole. 


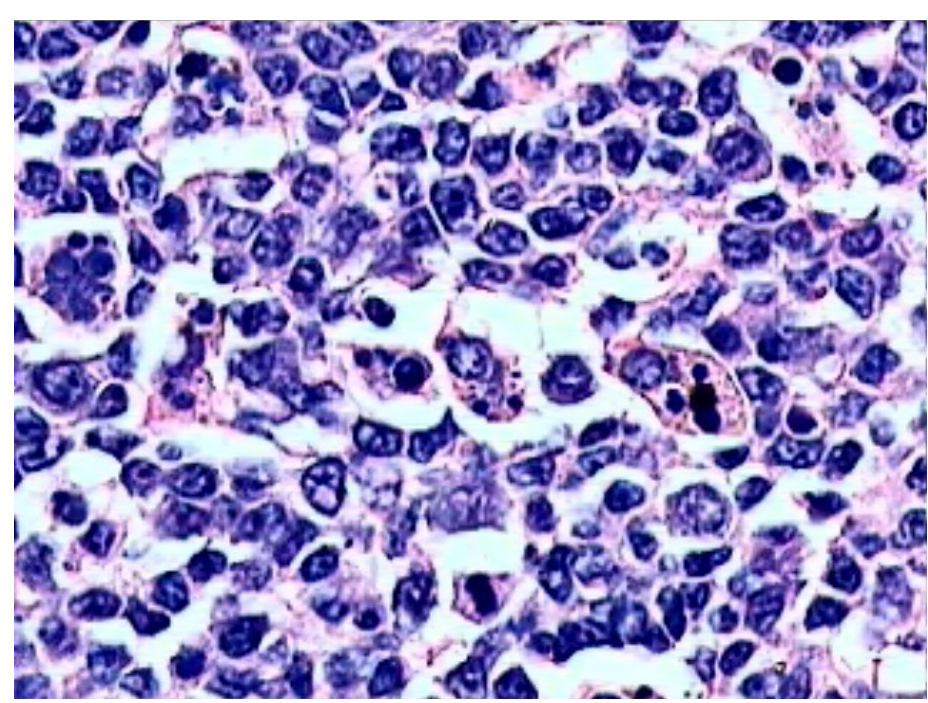

FIGURE 5 - Microscopic view of the inferior splenic pole of the rats, 10 days after SSL/IP. The white pulp contained slight lymphoid hyperplasia. In the red pulp, we observed sinusoidal dilatation with endothelial hyperplasia and mild to moderate congestion as well as macrophages with hemosiderin. Magnified 400 times.

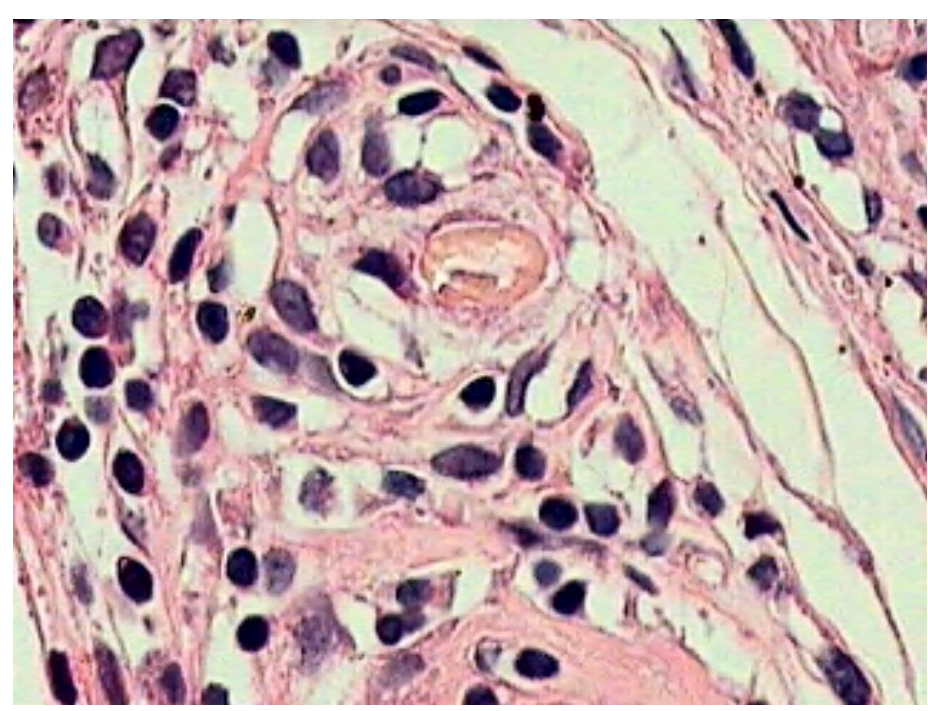

FIGURE 6 - Microscopic appearance of the inferior splenic pole of rats on day 80 after SSL/IP. The white pulp shows moderate lymphoid hyperplasia. The red pulp shows collapsed sinusoids with mild endothelial hyperplasia. A slight increase in the amount of lymphocyte traffic and the presence of hemosiderin-containing macrophages were observed. Samples from the inferior pole contained a higher concentration of macrophages with hemosiderin, and sinusoidal dilatation was also seen. Stromal sclerosis was not observed in samples from the inferior pole. Magnified 400 times.

\section{Discussion}

Because of its important functions, the spleen should be partially or fully preserved. This resolve should only be strengthened by the realization that this organ has functions that are still unknown. In cases of splenic trauma, medical (nonoperative) therapy can be attempted in children ${ }^{14}$ and adults ${ }^{15}$. In these circumstances, of course, the patient should be hospitalized and closely monitored. When surgery becomes necessary, spleen-conserving operations such as splenorrhaphy ${ }^{16}$, vascular occlusion $^{17-22}$ and partial splenectomy ${ }^{23-26}$ should be attempted. If the organ has been completely destroyed, autoimplantation should be attempted ${ }^{27}$. Given that operations on the spleen often require extensive, painful, unsightly incisions that can result in loss of function, abdominal laparoscopy has been used to perform splenic operations in the last several years ${ }^{28-30}$. Partial splenectomy with preservation of the superior pole has been described on experimental animals ${ }^{12}$, as has splenic tissue implantation by laparoscopy ${ }^{30}$ and an experimental model of laparoscopic splenectomy ${ }^{31}$. This study describes spleen-conserving surgery via laparoscopy, this time with preservation of the inferior pole, a technique already described by conventional access ${ }^{19}$.

At the beginning of this study, a pilot study was necessary to devise several technical improvements. We initially had difficulty achieving ideal pneumoperitoneum. The rats underwent general anesthesia without intubation or paralysis, and they displayed no relaxation of the abdominal wall and breathed spontaneously. This complicated the pneumoperitoneum technique. Ideal pneumoperitoneum was finally achieved in our study under $4 \mathrm{mmHg}$ pressure. The trocar position was optimized to yield the largest possible angle $\left(0-90^{\circ}\right)$ between the working clamps, the best position for a surgeon to work in, as it is otherwise difficult to handle the instruments during operations. These improvements in technique showed that the best trocar positions were a) 1 st trocar $(10-\mathrm{mm})$ in the left lower quadrant (optical port to 30 degrees), b) 2nd trocar $(5-\mathrm{mm})$ in the right subcostal region on a line that intersects the junction of the distal third of the clavicle, and c) 3rd trocar $(5-\mathrm{mm})$ in the right lower quadrant. In the pilot study, we developed an efficient way of fixing the trocars in the abdominal wall with rings cut-off from 3.0 mononylon silicone hose. The 3-0 mononylon wire was used so that the trocar would not fall out of the abdominal cavity. Silicone rings ( $5 \mathrm{~mm}$ in diameter), made by cutting silicone tubing similar to that used in conventional vacuum apparatus, were placed around the trocar ends, allowing only a short length to penetrate the abdominal cavity, thus preventing the trocars from entering the abdomen too deeply. These procedures allowed wide access to the abdominal cavity, making the intended operation possible. Subtotal laparoscopic splenectomy was performed using conventional access techniques to the spleen ${ }^{25}$. In addition to these precautions, two others were taken during the operation that followed the author's clinical SSL/IP technique ${ }^{13}$ : a) The first was to not position the inferior pole against the greater stomach curvature, in order to avoid twisting the remainder of the spleen. This twist is made possible by the long inferior pole pedicle (about $1 \mathrm{~cm}$ ). Experience with the SSL/IP technique on rats previously showed that positioning the inferior pole against the stomach resulted in a high incidence of necrosis of the remaining spleen (data not shown). The inferior pole should be placed in the abdominal cavity with its cut surface facing anteriorly. After this maneuver, the greater omentum falls naturally over the pole, which can be beneficial. b) The second precaution was to preserve the thin peritoneal membrane that connects the greater antral curvature to the inferior splenic pole, in order to maintain these organs in their anatomical position, i.e., with the IP's cut surface facing anteriorly. 
In Group 2, two animals died in the immediate postoperative period, and one died in the late postoperative period. Autopsy was unable to determine the cause of death of the animals that died in the late postoperative period. For animals that died during the immediate postoperative period, it is possible that the cause of death was an overdose of anesthesia and/or the technic of the pneumoperitoneum, since the animals did not wake up after surgery. In the late postoperative period, it was not possible to pinpoint the cause.

The technique was feasible in all animals after initial difficulties were overcome in the pilot study. No accidents occurred during surgery that could have jeopardized the outcome of surgery. The animals had excellent postoperative courses and even gained weight. The average inferior pole percentage was greater on postoperative day 80 than on day 10 . This suggests that the splenic remnant grew over time, as described by Paulo et al. ${ }^{32}$ In another partial splenectomy model, growth was also seen in the inferior pole ${ }^{33}$. This is a promising observation, as it suggests that splenic function can improve, and was demonstrated in previous work ${ }^{5}$. Bradshaw and Thomas ${ }^{34}$ reported that the greater the splenic remnant, the greater the protection against sepsis, and calculated that $25 \%$ residual splenic tissue constituted the critical mass for retaining normal phagocytic function. This report has been accepted by most authors who previously argued that the minimum critical mass required to maintain splenic function is more than $25 \%$ of the total splenic mass ${ }^{35}$. In an experimental study in rats, Van Wick et al. ${ }^{36}$ considered it necessary to maintain $1 / 3$ of the total spleen tissue in order to restore splenic function. In our study, the mass percentages on the 10th and 80th days were $53.67 \pm 11.59 \%$ and $62.69 \% \pm 6.89 \%$, respectively. Based on these results, we expect that the IP will eventually be able to carry out all splenic functions.

In our macroscopic analysis of the inferior pole, we noted that 17 splenic remnants from the 20 animals remaining appeared to be macroscopically normal. However, two of the 20 animals died during the immediate postoperative period, and their inferior poles were analyzed within the same timeframe. This examination was inherently limited by the impossibility of knowing how these poles would have evolved by the 80 th day. Thus, our mass percentage calculations were based on 17 animals, among which only one pole displayed necrosis. However, our calculation of the percent feasibility of SSL/IP was based on results from all 20 animals. From these calculations, we found that the percentage of viable poles was $94.1 \%$ and that the percent feasibility $100 \%$. Necrosis with abscess occurred in one case and may have been caused by torsion of the pedicle or a pedicle that was not long enough to reach the pole. It is important to remember that some technical conditions must also be met in splenectomy in order to preserve the inferior pole. Other precautions, such as avoiding division of the thin peritoneal fold between the greater curvature of the antrum and the inferior pole and preventing fixation of the inferior pole in any one location have been described elsewhere.

Microscopic analysis of the inferior pole on the 10th day found no differences compared to microscopic analysis of the superior portion during the same period. However, on day 80 , lymphoid hyperplasia of the inferior pole was increased (slight at day 10 , moderate at day 80 ), and concentrations of hemosiderincontaining macrophages were higher in samples from the inferior pole compared to those from the superior portion. Taken together, these observations suggest growth of the inferior pole.

Further work by surgical specialists is needed to demonstrate the feasibility, efficacy and safety of SSL/IP using this technique. The SSL/IP can be used in other conservative splenic operations to treat traumatic and non-traumatic disorders of the spleen ${ }^{13}$. Because it retains all the benefits of laparoscopy, including faster postoperative recovery, decreased endocrine response to trauma, lower risk of infection, better cosmetic and functional outcomes, and early hospital discharge.

\section{Conclusion}

Subtotal splenectomy with preservation of the inferior pole by laparoscopy was feasible and safety. The lower splenic pole was viable in $94.1 \%$ of animals.

\section{References}

1. Cadili A, de Gara C. Complications of splenectomy. Am J Med. 2008;121(5):371-5.

2. Sumaraju V, Smith LG, Smith SM. Infectious complications in asplenic hosts. Infect Dis Clin North Am. 2001;5(2):551-65.

3. Andersson R, Alwmark A, Bengmark S. Outcome of pneumococcal challenge in rats after splenic artery ligation or splenectomy. Acta Chir Scand. 1986;152:15-7.

4. Aviram M, Brook JG, Tatarsky, Levy Y, Carter A. Increased low-density lipoprotein levels after splenectomy: a role for the spleen in cholesterol metabolism in myeloproliferative disorders. Am J Med Sci. 1986;291(1):25-8.

5. Paulo DNS, Lázaro da Silva A. Lipídios plasmáticos após esplenectomia total e parcial em cães. Rev Col Bras Cir. 2001;28:264-70.

6. Asai K, Kuzuya M, Naito M, Funaki C, Kuzuya F. Effects of splenectomy on serum lipids and experimental atherosclerosis. Angiology. 1988;39(6):497-504.

7. Mühe E. Long-term follow-up after laparoscopic cholecystectomy. Endoscopy. 1992;24(9):754-8.

8. Mouret P. Celioscopic surgery. Evolution or revolution? Chirurgie. 1990;116(10):829-32.

9. Delaitre B, Maignien B. Splenectomy by the laparoscopic approach. Report of a case. Presse Med. 1991;20(44): 2263.

10. Poulin EC, Thibault C, DesCôteaux JG, Cote G. Partial laparoscopic splenectomy for trauma. Surg Laparosc Endosc. 1995;5:306-10.

11. Espert JJ, Targarona EM, Bombuy E, Setoain J, Visa J, Trias M. Evaluation of risk of splenosis during laparoscopic splenectomy in rat model. World J Surg. 2001;25(7):882-5.

12. Petroianu A, Berindoague Neto R. Esplenectomia subtotal por via laparoscópica em cães. Rev Col Bras Cir. 2006;33(5):305-10.

13. Paulo DNS, Lázaro da Silva A, Cintra LC, Bof AM, Santiago DC, Ribeiro GB. Esplenectomia subtotal, em cães, com preservação do pólo inferior suprido por vasos do ligamento gastroesplênico. Rev Col Bras Cir. 1999;26:147-52.

14. Kakkasseril JS, Stewart D, Cox JA. Changing treatment of pediatric splenic trauma. Arch Surg. 1982;117:758-9.

15. Brasel KJ, DeLisle CM, Olson CJ, Borgstrom DC. Splenic injury: trends in evaluation and management. J Trauma. 1998;44:283-6.

16. Abrantes WL, Lucena MM, Schlobach MC. Cirurgia conservadora do trauma esplênico na criança. Rev Assoc Med Bras. 1994;40(2):113-7. 
17. Haan JM, Bochicchio GV, Kramer N, Scalea TM. Nonoperative management of blunt splenic injury: a 5-year experience. J Trauma. 2005;58(3):492-8.

18. Iwase K, Higaki J, Mikata S, Tanaka Y, Yoshikawa M, Hori S, Osuga K, Kosugi S, Tamaki T, Kamiike W. Laparoscopically assisted splenectomy following preoperative splenic artery embolization using contour emboli for myelofibrosis with massive splenomegaly. Surg Laparosc Endosc Percutan Tech. 1999;9(3):197-202.

19. Campbell R, Marik PE. Severe autoimmune hemolytic anemia treated by paralysis, induced hypothermia, and splenic embolization. Chest. 2005;127(2):678-81.

20. Ortyl W, Turowska B, Ciazynski M, Zarborski G, Turowski G. Anti-N antibodies after ligation of splenic artery in rabbits. Mater Med Pol. 1989;21:35-7.

21. Warshaw A L. Conservation of the spleen with distal pancreatectomy. Arch Surg. 1988;123:550-3.

22. Ueno T, Okam, Nishihara K, Yamamoto K, Nakamura M, Yahara N, Adachi T. Laparoscopic distal pancreatectomy with preservation of the spleen. Surg Laparosc Endosc Percut Tech. 1999;9(4):290-3.

23. Campos-Christo M. Esplenectomias parciais regradas. O Hospital. 1959;56(4):93-8.

24. Petroianu A. Esplenectomia subtotal e anastomose esplenorrenal proximal para o tratamento da hipertensão portal. Rev Bras Cir. 1983;73(2):101-4.

25. Paulo DNS,Paulo ICA, Kalil M, Vargas PM, Silva AL, Baptista JF, Guerra AJ. Subtotal splenectomy preserving the lower pole in rats: technical, morphological and functional aspects. Acta Cir Bras. 2006;21(5):1-10.

26. Paulo ICA, Paulo DNS, Cintra LC, Santos MCS, Rodrigues H, Ferrari TA, Azevedo TCV, Lázaro da Silva A. Preservative spleen surgery and hyperbaric oxygen therapy. Acta Cir Bras. 2007;22 Suppl 1:21-8.

27. Malago R, Reis NS, Araújo MR, Andreollo NA. Late histological aspects of spleen autologous transplantation in rats. Acta Cir Bras. 2008;23(3):274-81
28. Vasilescu C, Stanciulea O, Colita A. Stoia R, Moicean A, Arion C. Splenectomia subtotala laparoscópica in tratamentul microsferocitozei ereditare. Chirurgia. 2003;98:571-6.

29. Mayberry JC, Sheppard BC, Mullins RJ. Laparoscopic management of an enlarging subcapsular splenic hematoma. J Trauma. 1998;44(3):565-7.

30. Petroianu A, Cabezas-Andrade MA, Neto RB. Laparoscopic splenic autotransplantation. Surg Laparosc Endosc Percutan Tech. 2006;16(4):259-62.

31. Costa VA, Oliveira FM, Oliveira Jr LC, Carreiro MC, Guimarães P. An experimental model of laparoscopic splenectomy in rats. Acta Cir Bras. 2003;18(6):553-6.

32. Paulo DNS, Ramos BF, Zanetti FR. Growth of the lower spleen pole remaining after subtotal splenectomy in rats. Acta Cir Bras. 2008;23(2):125-9.

33. Torres OJM, Macedo EL, Picciani ERG, Nunes PMS, Costa JVG, Carvalho AB, Lobato Jr PS. Histological study of splenic regeneration in rats underwent to subtotal splenectomy. Acta Cir Bras. 2000;15(2):1-12. 34. Bradshaw PH, Thomas CG. Regeneration of splenic remnants after partial splenectomy in rats. J Surg Res. 1982;32(2):176-81.

35. Pisters PWT, Pachter HL. Autologus splenic transplantation for splenic trauma. Ann Surg. 1994;219:225-35.

36. Van Wick DB, White MH, White CL. Critical splenic mass for survival from experimental pneumococcemia. J Surg Res. 1980;28:14-7.

\section{Acknowledgments}

Rafael Melo Silva, Graduate Student, Emescam; Bernardo Faria Ramos, Resident of Otorhinolaryngology, Clinical Hospital, University of Sao Paulo and Fernando Roberte Zanetti, Resident of Ophthalmology from UNICAMP, helped with technical procedure.

\section{Correspondence:}

José Jorge da Silva

Rua Desembargador Augusto Botelho, 108/904

29101-110 Vila Velha-ES Brasil

drjjorge@gmail.com
Conflict of interest: none Financial source: Solidary Institute
Received: July 27, 2010

Review: September 21, 2010

Accepted: October 26, 2010 